\title{
Innovative treatments for severe refractory asthma: how to choose the right option for the right patient?
}

This article was published in the following Dove Press journal:

Journal of Asthma and Allergy

30 August 2017

Number of times this article has been viewed

\section{Francesco Menzella' \\ Carla Galeone' \\ Francesca Bertolini ${ }^{2}$ \\ Claudia Castagnetti' \\ Nicola Facciolongo'}

'Department of Medical Specialties, Pneumology Unit, IRCCS- Arcispedale Santa Maria Nuova, Reggio Emilia, Italy; ${ }^{2}$ Department of Animal Science, lowa State University, Ames, IA, USA

Correspondence: Francesco Menzella Department of Medical Specialties, Pneumology Unit, IRCCS- Arcispedale Santa Maria Nuova, Viale Risorgimento 56, 42 I 23 Reggio Emilia, Italy

Tel +39052 2296073

Fax +39052 2296182

Email menzella.francesco@ausl.re.it
Abstract: The increasing understanding of the molecular biology and the etiopathogenetic mechanisms of asthma helps in identification of numerous phenotypes and endotypes, particularly for severe refractory asthma. For a decade, the only available biologic therapy that met the unmet needs of a specific group of patients with severe uncontrolled allergic asthma has been omalizumab. Recently, new biologic therapies with different mechanisms of action and targets have been approved for marketing, such as mepolizumab. Other promising drugs will be available in the coming years, such as reslizumab, benralizumab, dupilumab and lebrikizumab. Moreover, since 2010, bronchial thermoplasty has been successfully introduced for a limited number of patients. This is a nonpharmacologic endoscopic procedure which is considered a promising therapy, even though several aspects still need to be clarified. Despite the increasing availability of new therapies, one of the major problems of each treatment is still the identification of the most suitable patients. This sudden abundance of therapeutic options, sometimes partially overlapping with each other, increases the importance to identify new biomarkers useful to guide the clinician in selecting the most appropriate patients and treatments, without forgetting the drug-economic aspects seen in elevated direct cost of new therapies. The aim of this review is, therefore, to update the clinician on the state of the art of therapies available for refractory asthma and, above all, to give useful directions that will help understand the different choices that sometimes partially overlap and to dispel the possible doubts that still exist.

Keywords: severe asthma, phenotypes, monoclonal antibodies, IL-5, bronchial thermoplasty, biomarkers

\section{Introduction}

In the last few years, there has been an increased understanding of the etiopathogenetic mechanisms and phenotypes of asthma, particularly in the field of molecular biology and immunogenetics. Through this knowledge, it has been possible to develop new therapeutic approaches for the treatment of several asthmatic phenotypes. This is increasing the potential to meet the unmet needs of patients with unsatisfactory control of asthma. These patients suffer from the side effects of systemic steroids, and this may have a high impact on the economic resources because of frequent access to health services.

For over a decade, the only available biologic therapy has been omalizumab, a monoclonal antibody (mAb) which is targeted to anti-IgE and is used for a specific subpopulation of patients with uncontrolled IgE-mediated allergic asthma. For these patients, omalizumab has been very effective and has made it possible to change the clinical history of patients that would have otherwise been condemned to a limited 
and burdensome life due to their respiratory conditions. ${ }^{1}$ For a long time, patients not eligible or not responsive to this treatment had to wait for the development of different therapies. Recently, new drugs and nonpharmacologic options are becoming available, showing encouraging results:

1. Biologic therapies with different mechanisms of action and targets. One of these molecules, the antiinterleukin 5 (anti-IL-5) mAb mepolizumab, has been recently approved for marketing. Other mAbs and new anti-inflammatory agents, such as prostaglandin receptor antagonists, will be available in the coming years. ${ }^{2}$

2. Nonpharmacologic therapies, such as the bronchial thermoplasty (BT): This is still a controversial therapy because the efficacy is not always convincing and several aspects need to be clarified. This therapy may be applied on a large scale only after a clarification of all the concerns and doubts. As an invasive instrumental method, it may remain limited to centers with adequate experience and expertise. However, BT is showing extremely interesting results in terms of improving the quality of life (QoL) and reducing asthma exacerbation. ${ }^{3}$

The availability of these new therapies enables addressing the patients to the most appropriate treatment and reducing therapeutic dropouts (Figure 1). These important actions can be facilitated by the identification of new biomarkers.

In this review, we will describe the therapies previously mentioned focusing on the treatments that are already available or that are on the most advanced stage of development. We will discuss the overlapping aspects of some of these treatments and their application in clinical practice. In this regard, the future availability of new molecules that are specific for different targets is gaining attention, considering that these targets are sometimes present in the same phenotype. This will make it difficult for the clinical task to choose the most suitable and the most effective drug. Understanding the role of the various therapeutic options, their differences and similarities and the doubts that still exist will simplify the clinical decision-making process and will allow obtaining the best result for the patient.



Figure I Molecular targets of biologic drugs: action of the pathogenetic pathway of asthma at different levels. Abbreviations: IFN, interferon; IL, interleukin; TNF, tumor necrosis factor; APC, antigen presenting cell. 


\section{From asthma phenotyping to personalized medicine}

It is known that patients with asthma exhibit different levels of severity of their pathology, as well as several phenotypes and endotypes. ${ }^{4}$ This subdivision is primarily based on several clinical and immunological characteristics: allergic and nonallergic or "T2-high" and "T2-low". The main inflammatory phenotypes can be eosinophilic or noneosinophilic, where the latter is subdivided into neutrophil or pauci-granulocytic. ${ }^{5}$

The identification and definition of the endotypes has started only recently. ${ }^{6}$ This approach can be described as a single and distinct functional and physiopathologic mechanism that would enable a better use of existing drugs by identifying patient subgroups in order to find the more suitable treatment. ${ }^{6}$ Each endotype includes several asthmatic phenotypes that can be considered as "phenotypic clusters". However, further studies need to be preformed for a complete definition. ${ }^{7,8}$ The phenotype-based therapy will strongly benefit from the future discoveries of genomics, proteomics and transcriptomics which are the subdisciplines of systems biology that will contribute to making the customization of therapies a real possibility. ${ }^{9}$

\section{IgE-mediated asthma and anti-IgE mAbs}

In IgE-mediated asthma, the exposure to allergens results in an increased inflammation and worsening of respiratory function parameters. The cardinal role of this process is carried out by the $\operatorname{IgE}$ antibodies that bind to high-affinity (FceRI) and low-affinity (FceRII or CD23) receptors on the surface of mast cells and basophils and lead to subsequent degranulation and release of mediators. ${ }^{10}$

Omalizumab (Xolair ${ }^{\circledR}$ ) is a murine mAb (MAE11) that has been applied in clinical practice since 2005 for the treatment of severe allergic refractory asthma in patients sensitized to perennial allergens with serum IgE levels in the range of 30-1500 IU/mL (Figure 2; Table 1). This biologic is constructed by a somatic cell hybridization method, whose

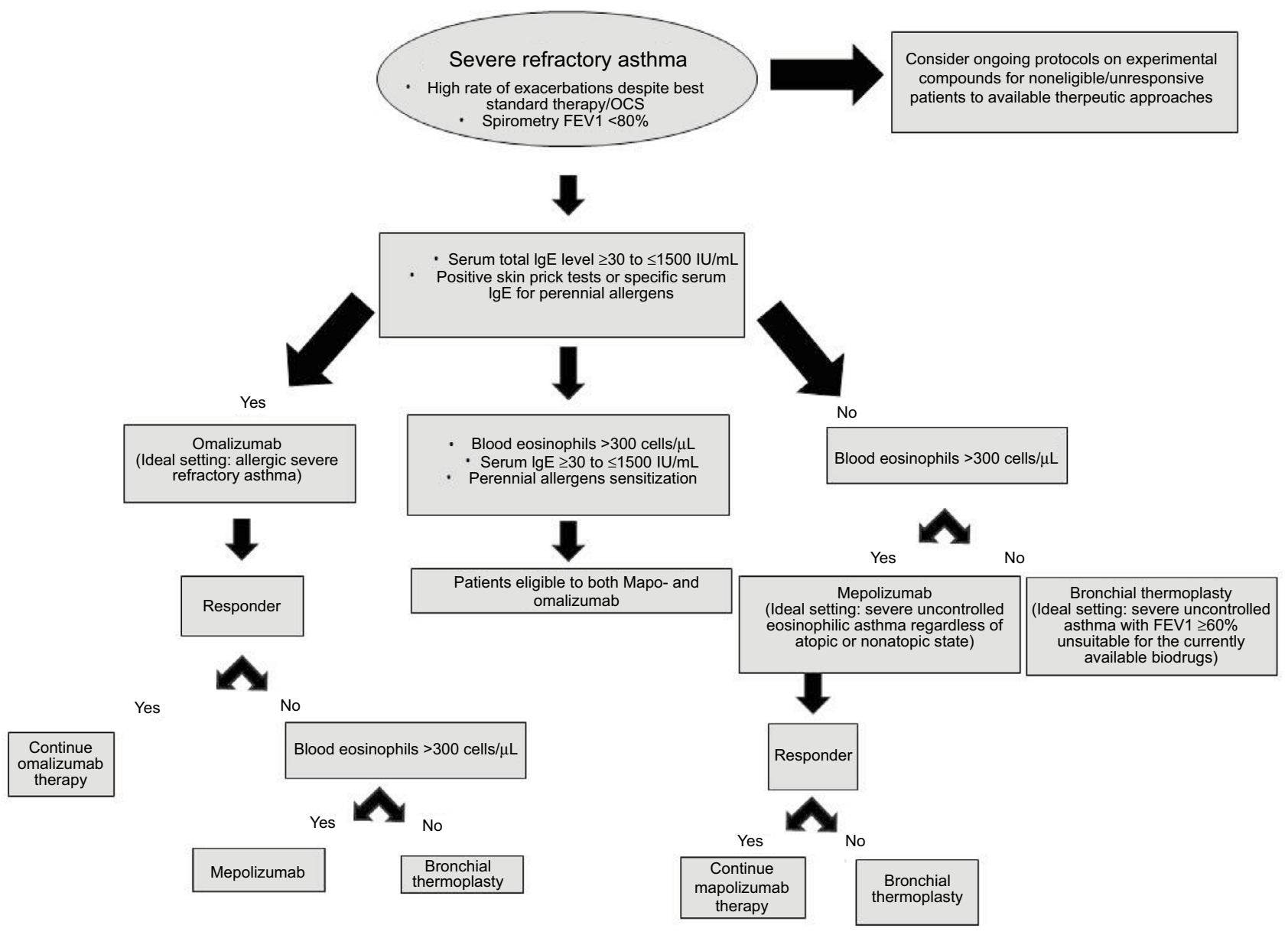

Figure 2 Flowchart for the selection of different treatment options. Abbreviation: OCS, oral corticosteroids. 
Table I Costs and treatment duration

\begin{tabular}{|c|c|c|c|c|}
\hline $\begin{array}{l}\text { ERS/ATS } 2014 \text { guideline } \\
\text { recommendation' }\end{array}$ & $\begin{array}{l}\text { Asthma } \\
\text { treatment }\end{array}$ & Costs in Italy & Costs in USA & $\begin{array}{l}\text { Treatment interval/ } \\
\text { duration }\end{array}$ \\
\hline $\begin{array}{l}\text { Patients with severe uncontrolled } \\
\text { allergic asthma: serum total lgE levels } \\
\geq 30 \text { to } \leq 1500 \mathrm{IU} / \mathrm{mL} \\
\text { Positive skin prick test or specific } \\
\text { serum IgE for perennial allergens }\end{array}$ & Omalizumab & $\begin{array}{l}€ I 5.150 \text { average cost per } \\
\text { patient per year }{ }^{2, a}\end{array}$ & $\begin{array}{l}\$ 14.400-\$ 28.800 \text { per patient } \\
\text { per year, } 3 \text {,a }\end{array}$ & Every 2 or 4 weeks/lifetime \\
\hline $\begin{array}{l}\text { Patients with hypereosinophilic severe } \\
\text { uncontrolled asthma: blood eosinophil } \\
\text { levels }>300 \text { cells } / \mu \mathrm{L}\end{array}$ & Mepolizumab & $\begin{array}{l}€ \mid 3.033 \text { per patient per } \\
\text { year }^{4}\end{array}$ & $\begin{array}{l}\$ 10.000-\$ 15.000 \text { per patient } \\
\text { per year }{ }^{5}\end{array}$ & Every 4 weeks/lifetime \\
\hline $\begin{array}{l}\text { Patients with severe uncontrolled } \\
\text { asthma: not eligible or unresponsive } \\
\text { to biodrugs }{ }^{\S}\end{array}$ & $\begin{array}{l}\text { Bronchial } \\
\text { thermoplasty }\end{array}$ & $\begin{array}{l}€ 6.550 \text { per patient per } \\
\text { year per procedure } \\
\text { (total cost } € \mid 9.650)^{2, a} \\
\text { Alair system }(€ 35.000 \text { ) }\end{array}$ & $\begin{array}{l}\$ 7.500 \text { per three Alair catheters } \\
\text { in addition of purchase of the } \\
\text { Alair system }(\$ 60.000)^{6}\end{array}$ & $\begin{array}{l}\text { Three procedures } \\
\text { performed at } 20 / \text { day } \\
\text { intervals }\end{array}$ \\
\hline $\begin{array}{l}\text { Patients with hypereosinophilic severe } \\
\text { uncontrolled asthma: blood eosinophil } \\
\text { levels }>400 \text { cells } / \mu \mathrm{L}\end{array}$ & Reslizumab & Not yet available & Not yet available & Every 4 weeks/lifetime \\
\hline
\end{tabular}

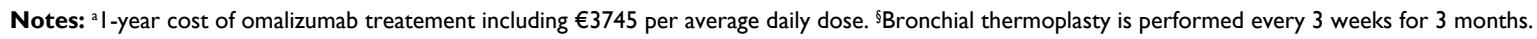
Abbreviation: ERS/ATS, European Respiratory Society/American Thoracic Society

main feature is to present a paratope capable of binding to FceRI and FceRII receptors of basophils, dendritic cells and mast cells. $^{11}$

To evaluate the effectiveness of omalizumab in patients with severe allergic uncontrolled asthma, several randomized clinical trials (RCTs) have been recently conducted. These studies demonstrated its efficacy and safety, with a significant reduction in the frequency of asthma exacerbations (up to 50\%) and improvement in the QoL, ${ }^{12}$ as well as reduction in the use of oral corticosteroids (OCSs). ${ }^{12}$ The measurement of total IgE levels and body weight makes it possible to define its dosage, making this treatment the first to define a biologic treatment for asthma based on the use of a biomarker. ${ }^{13}$ This treatment showed good efficacy even in patients with nonallergic asthma, most often treated for longer periods, ${ }^{14}$ giving credit to the hypothesis that there is a local IgE production even without systemic sensitization. ${ }^{15}$ Other studies have confirmed its effectiveness in inner city children with resistant asthma, ${ }^{16}$ as well as in the prevention of seasonal exacerbations, thanks to a better interferon- $\alpha$ response to rhinoviruses. ${ }^{17}$ Recently, omalizumab has also been approved for the treatment of spontaneous chronic urticaria, ${ }^{18}$ while the increasing number of positive results on nasal polyposis provides new insights into this pathology that is often associated with asthma, ${ }^{19}$ regardless of the atopic status.

Based on the current data, omalizumab is indicated for continuing the treatment for an indefinite period, as the $\operatorname{IgE}$ levels and the number of FceRI receptors tend to increase 3-4 weeks after its suspension. In this regard, several studies have confirmed that discontinuation of this treatment results in a worsening of asthma control, especially in patients with higher levels of eosinophilia, periostin and FeNO. These molecules seem to better respond to omalizumab drug, but they are the first to decay after suspension of the treatment. ${ }^{20,21}$ Recent studies also show an increase in clinical efficacy in the long term (up to 9 years of follow-up), ${ }^{22}$ with a favorable cost-effectiveness profile. ${ }^{23}$

Considering the intrinsic limitations of omalizumab, the subsequent evolution could be the application of mAbs with greater avidity for IgE, such as quilizumab (RG7449). This is a newly humanized $\mathrm{mAb}$ that binds to the M1 segment of the membrane IgE and targets the B lymphocytes before they are activated to produce IgE. The Controlled on Inhaled Steroids and a Second Controller trial is a 36-week, Phase II, randomized, placebo-controlled, double-blind study whose results have been recently published. ${ }^{24}$ These results show that quilizumab has a good safety profile and is associated with specific decrease in IgE serum levels up to $40 \%$, without significant impact on exacerbations, respiratory functions and symptoms. ${ }^{25}$

Two other RCTs were designed to determine the safety, pharmacokinetics and efficacy of quilizumab in patients with allergic rhinitis. ${ }^{26,27}$ In both studies, the treatment was tolerated and showed a significant reduction in persistent specific serum IgE up to 6 months after withdrawal, also blocking the production of new IgE after allergen challenge and reducing the eosinophils in induced sputum by over $50 \%$ compared to placebo. ${ }^{28}$

Another anti-IgE mAb is QGE031 (ligelizumab), a novel anti-IgE agent whose first studies showed a greater suppression of free IgE than omalizumab, including those with higher IgE levels. ${ }^{29}$

Despite the promising initial data, the Phase II study CQGE031B2201 failed to meet the primary objective of dem- 
onstrating superiority of QGE031 versus placebo (Novartis Pharmaceuticals, unpublished data). ${ }^{30}$ Consequently, two other related Phase II trials were suspended following the failure of the core study.

Even if the premises were not positive, in a recent doubleblind, parallel-group, multicenter study, 37 patients with mild allergic asthma were randomized to subcutaneous (SC) omalizumab, placebo or QGE031 at 24, 72 or $240 \mathrm{mg}$ every 2 weeks for 10 weeks. ${ }^{31}$ Inhaled allergen challenge and skin tests were performed before dosing at 6,12 and 18 weeks, and blood samples were collected until 24 weeks after the first dose. Ligelizumab appears to be more effective than omalizumab in terms of skin and inhalation response, demonstrating that it may be the most effective successor to omalizumab.

\section{Eosinophils and IL-5}

The eosinophilic granulocyte maturation, their recruitment and survival in the respiratory tract are determined by IL-3 and granulocyte-macrophage colony-stimulating factor, but above all by IL-5, which is the most important IL for the determination of eosinophilic airway inflammation. IL-5 induces the final differentiation of B cells activated into antibody-forming cells and enhances the proliferation and differentiation of the eosinophil precursors into mature eosinophils. ${ }^{32}$ Murine experimental models showed that it may be involved in airway remodeling, so administration of IL-5 antibodies almost completely blocks the peribronchial and subepithelial fibrosis induced by inhaled allergens. ${ }^{33}$ Eosinophils play a key role in several chronic respiratory diseases and can affect their severity. ${ }^{32}$ In asthma, eosinophilia is present in about $40 \%-60 \%$ of cases, with a direct correlation between the severity of the disease and the presence of blood eosinophils and sputum. ${ }^{34}$

Eosinophilia is associated with a wide variety of conditions such as asthma, atopic diseases, viral infections, hypersensitivity to drugs and neoplastic conditions. For these reasons, several anti-IL-5 mAbs such as mepolizumab $\left(\right.$ Nucala $\left.^{\circledR}\right)$, reslizumab $\left(\right.$ Cinqair $\left.^{\circledR}\right)$ and benralizumab have been studied.

Mepolizumab is a humanized IgG1 nonglycosylated IgG1 antibody that binds to IL-5 and prevents the binding of IL-5 to its receptor. Early studies involved the application of mepolizumab for the treatment of idiopathic hypereosinophilic syndrome $^{35}$ and Churg-Strauss syndrome or eosinophilic granulomatosis and polyangiitis, where a significant reduction in the use of OCS and a better control of the disease was observed. ${ }^{35}$ Other studies demonstrated that this molecule was ineffective in terms of improvement of respiratory function parameters (bronchial hyperresponsiveness, FEV1, PEF) ${ }^{36}$ and better asthma control (decreased rate of exacerbation) despite a decline in eosinophils in the blood and sputum. ${ }^{37}$ Based on later observations, described below, it was clear that there was a selection bias, concerning the blood eosinophilia and the severity of asthma criteria. The patients were not selected on the basis of blood eosinophils.

Two subsequent RCTs clearly showed how initially intravenous and SC mepolizumab could reduce the need for steroids and the number of exacerbations in patients with severe asthma with eosinophils $>300$ cells $/ \mu \mathrm{L}$, with less visible but positive effects on respiratory function parameters. ${ }^{38,39} \mathrm{~A}$ third registrative RCT confirmed the efficacy of mepolizumab in terms of reducing exacerbations, improving the QoL calculated by the Asthma Control Questionnaire 5 questionnaire and, above all, having an average reduction of $50 \%$ in the dose of OCS. ${ }^{40}$ A recent MUSCA trial (mepolizumab addon therapy on health-related quality of life and markers of asthma control in severe eosinophilic asthma) has confirmed that this drug significantly improved the health-related QoL in patients with severe eosinophilic asthma and had a security profile similar to placebo. ${ }^{41}$ In 2015 , mepolizumab was approved by the US Food and Drug Administration (FDA) and the European Medicines Agency for the treatment of severe eosinophilic asthma at a dose of $100 \mathrm{mg}$ SC every 4 weeks (Figure 2; Table 1). ${ }^{42,43,45}$

A second $\mathrm{mAb}$ anti-IL-5 is reslizumab. This drug has been studied in patients with uncontrolled eosinophilic asthma with a blood eosinophil level $>400$ cells $/ \mu \mathrm{L}$, showing a meaningful reduction of sputum eosinophil count, an improvement in QoL, FEV1 and control of the disease in terms of reducing exacerbations. ${ }^{44}$ The administration of reslizumab showed improved symptoms and QoL, even in case of nasal polyposis. ${ }^{44}$ The limitation of this drug may be the intravenous administration, since it is FDA approved only with this indication. ${ }^{45}$

Benralizumab (MEDI-563) is an IgA1 mAb that binds the epitope on the $\alpha$-subunit of the IL- 5 receptor. It has been shown to reduce blood eosinophils and their precursors through the induction of antibody-mediated cell cytotoxicity (ADCC). ${ }^{46}$ Therefore, its molecular mechanism is completely different from that of mepolizumab. The benralizumab constant region $(\mathrm{Fc})$ is afucosylated, leading to greater affinity for the Fc-gamma III receptor (Fc $\gamma \mathrm{RIII}$ ) on the surface of the mast cells, basophils and natural killer cells, through which it induces ADCC on eosinophils and basophils. ${ }^{47}$ This involves a nearly complete depletion of eosinophils in sputum and tissues (90\% and $96 \%$, respectively) and a total disappearance 
in the bone marrow and blood. ${ }^{48}$ In Phase I and II RCTs on patients with severe eosinophilic asthma and peripheral eosinophils $>300$ cells $/ \mu \mathrm{L}$, SC benralizumab showed promising results, especially in terms of reducing EDN and ECP inflammation and inflammatory mediators as well as causing a significant reduction in blood eosinophils. ${ }^{49,50}$

The main difference between benralizumab and other IL-5 $\mathrm{mAb}$ drugs is that benralizumab is independent of the circulating level of IL-5, which tends to increase during asthma exacerbations. The almost total depletion of eosinophils through ADCC prevents the effects caused by the activation by other related cytokines (IL-3 and granulocyte-macrophage colony-stimulating factor) that share the same receptor through the $\beta$ subunit. The absence of fucose sugar residue in the molecular structure of benralizumab results in a much higher affinity for the FcyRIIIa receptor, overcoming the inhibitory effects of serum blocking IgGs. ${ }^{47}$ These features resulted in excellent efficacy data in terms of reduction of exacerbation rate and improvement in FEV1, ${ }^{51,52}$ significant reduction $(75 \%)$ of the $\mathrm{OCS}^{53}$ average dose and a clear response after the first dose. ${ }^{54}$

\section{Block of IL-4/IL- I 3}

IL-4 and IL-13 are pleiotropic T-helper type 2 cytokines with a common pathway frequently associated with asthma and other atopic diseases such as atopic dermatitis. ${ }^{55}$ The main functions of IL-4 and IL-13 are the activation of the IgE isotype switch by plasma cells, the proliferation of $\mathrm{T}$ lymphocytes, especially $\mathrm{Th} 2$, in stimulation of expression of some adhesion molecules on endothelial cells (especially VCAM-1) and stimulation of smooth bronchial muscle contractility. High levels of IL-13 are found in sputum and bronchial biopsies of patients with severe asthma, often not responsive to the use of systemic and inhaled steroids. This confirms the role of this cytokine in corticosteroid resistance. ${ }^{56}$ Some interesting $\mathrm{mAbs}$ in development aim to target these fundamental cytokines such as dupilumab, lebrikizumab and tralokinumab.

The mAb dupilumab inhibits the biologic effect of both IL-4 and IL-13 by preventing their interaction with IL-4 receptor $\alpha$ subunit. Recent studies have shown that this drug results in a significant decrease in exacerbations and better control of symptoms and pulmonary function, with concomitant reduction of inflammatory biomarkers related to the activity of Th2 lymphocytes, but with effects independent of eosinophils in serum in patients with severe refractory asthma. ${ }^{57}$ Recent trials on dupilumab administered SC as an add-on therapy at dose ranging from 100 to $300 \mathrm{mg}$ showed an increase in pulmonary function and a significant reduction in severe exacerbations in patients with persistent asthma, without any difference in counting $( \pm 300$ cells $/ \mu \mathrm{L})$ but with a favorable safety profile. ${ }^{58,59}$ Dupilumab also confirmed a marked reduction in the biomarkers associated with Th2driven inflammation (TARC levels, eotaxin-3, FeNo). ${ }^{59}$

Lebrikizumab (MILR1444A) is another humanized mAb having a specific target of IL-13. Lebrikizumab administered SC at doses of 125, 250 and $500 \mathrm{mg}$ every 4 weeks showed an improved pulmonary function in extensive Phase II studies in patients with severe refractory asthma, with improved symptom control and reduced exacerbation, especially in the group with allergic phenotype with high levels of periostin and exogenous nitric oxide (FeNO). ${ }^{60}$ The improvement in FEV1 was also more apparent in the group with higher levels of periostin and FeNO, confirming the hypothesis that IL-13-driven phenomena are clinically important in these patients. ${ }^{61,62}$ Subsequently, two identical 52-week, Phase III studies had been conducted to assess the efficacy and safety of lebrikizumab in patients with uncontrolled asthma (LAVOLTA I and II). LAVOLTA I met its primary endpoint, showing a significant reduction in the rate of asthma exacerbations in people with higher levels of serum periostin or blood eosinophils. This study also showed a significant improvement in lung function. Unfortunately, these positive findings were not confirmed in LAVOLTA II, which did not show a significant reduction in asthma exacerbations. ${ }^{63}$

Another anti-IL-13 mAb is tralokinumab, whose development is facing major difficulties because the data that emerged from two Phase IIb RCTs are still not encouraging. Indeed, tralokinumab at doses ranging from 150 to $600 \mathrm{mg}$ given every 2 weeks or every 4 weeks did not reduce asthma exacerbation rates or improve ACQ6 score in patients with uncontrolled asthma compared to placebo, although improvements in FEV1 were observed in patients receiving the drug every 2 weeks. ${ }^{64,65} \mathrm{~A}$ post hoc analysis in the group of patients with higher IL-13 levels (10 $\mu \mathrm{g} \mathrm{Ml-1)}$ at the time of admission to the study showed numerically greater improvements in FEV1 than in subjects whose values were lower than these thresholds, suggesting that the presence of residual IL-13 was associated with a higher response in FEV1. ${ }^{65}$

\section{Antagonist of the prostaglandin D2 receptor}

Prostaglandin D2 (PGD2) is a prostanoid produced mostly by the mast cells in allergic diseases. The PGD2-induced vasodilatation and the subsequent increase in permeability are involved in inflammatory allergies. ${ }^{66}$ Prostanoid (DP) 
receptors and the homologous receptor mutant molecule expressed on Th2 (CRTH2) cells have been shown to be the major PGD2-related receptors that have central roles in the regulation of the functions of several cells crucial in allergic diseases. ${ }^{66}$

Fevipiprant (QAW039) is an antagonist of PGD2 receptor CRTH2, which is expected to provide benefit in asthma by binding to CRTH2 receptors on eosinophils, basophils and T lymphocytes in the blood and tissues, thus inhibiting the migration and activation of these cells into the airway tissues and blocking the PGD2-driven release of Th2 cytokines. ${ }^{67}$ QAW039 is an interesting and unique molecule with ongoing Phase II and III RCTs that are recruiting patients with severe refractory allergic asthma Steps 4-5 Global Initiative for Asthma 2016. Fevipiprant, compared to all other mAbs, has the advantage of daily oral administration at doses up to $500 \mathrm{mg}$. Preliminary data confirm a good safety profile and improvement of FEV1, especially in patients with more severe obstruction. ${ }^{68}$ Another Phase II study in patients with uncontrolled allergic asthma showed no improvement in pulmonary function. However, a subgroup analysis revealed that patients with impaired respiratory function (FEV1 $<70 \%$ ) had improved pulmonary function and asthma control when treated with QAW039. ${ }^{69}$ In a subsequent randomized, single-center, double-blind, parallelgroup, placebo-controlled study on 61 patients with moderateto-severe asthma, fevipiprant reduced eosinophilic airways and sputum inflammation and was well tolerated, confirming the good perspective of this drug for the near future. ${ }^{70}$

\section{Not only biologic therapies: BT}

BT is an endoscopic procedure approved by the FDA in 2010 for the treatment of severe refractory asthma. This method is essentially based on the delivery of $65^{\circ}$ radiofrequency by a disposable catheter with $2.0 \mathrm{~mm}$ diameter introduced into the fibrobroncoscope operating channel (Alair $\left.{ }^{\circledR}\right){ }^{70} \mathrm{BT}$ is a one-time procedure that is completed after three treatments performed $\sim 20$ days apart, and several studies have demonstrated its long-term safety and effectiveness in terms of reducing serious exacerbations, improving health-related QoL and reducing the number of working/school days lost for asthma. ${ }^{72-74}$ BT should always be used as an add-on treatment with the best standard care (Table 1). Due to its complex procedure, BT should always be performed in centers with adequate preparation and experience to handle possible intra- and postprocedure adverse events. ${ }^{75}$ Moreover, the significant increase in direct costs could represent another limiting factor. However, these costs are lower if compared with those associated with the use of biologic therapies for serious asthma (in particular, omalizumab), especially for long-term treatments, as demonstrated by several studies. ${ }^{76,77}$ There are still many open questions about the mechanism of action, selection of patients and their management. However, a reduction of airway smooth muscle and inflammation has been observed, ${ }^{78,79}$ also with regard to a possible reduction of blood eosinophils after BT. ${ }^{80}$ Some evidence reveals the possible effects of BT on the small airways, which is very important in asthma pathogenesis. ${ }^{81}$ It has also been argued that BT may influence the neuroendocrine epithelial cells, bronchial nerve endings, destruction of TRPV1 nerve receptors and the type- $\mathrm{C}$ unmyelinated fibers in the mucosa by interrupting central and local reflexes responsible for the activation of bronchospasm and bronchial hyperreactivity. ${ }^{82}$ All these aspects go beyond what was first hypothesized about the mechanisms of action, but they need further confirmation. However, several questions remain open regarding the phenotyping of patients and the long-term effects, but further improvements and clarifications will be expected in the next few years.

Based on the literature data and treatments available, BT may be already proposed for several patients: 1) patients with FEV $1 \geq 60 \%$ of the predicted, ${ }^{71}$ unsuitable for the currently available biodrugs (omalizumab or mepolizumab); 2) patients responsive to these mAbs and 3) patients who do not want to undergo biologic therapies with an indefinite duration (Figure 2). There are, however, studies on small patient groups such as Doeing et al's work on eight patients with severe functional impairment (FEV1 between 52\% and $37 \%$ of the predicted), where BT was found to be effective in five of them without causing worsening of respiratory function. ${ }^{83}$ BT may also be indicated in patients with frequent exacerbations and hospitalization, regardless of T1 or T2 phenotype $^{84}$ or respiratory function. Another potentially suitable subgroup could be composed of patients with severe steroid-resistant refractory asthma. ${ }^{85}$

\section{Growing role of biomarkers in asthma phenotyping and for the drug choice}

In clinical practice, asthma management and its follow-up are mainly based on respiratory function parameters that determine hyperreactivity and bronchial obstruction. However, these data do not always correlate with the levels and type of respiratory inflammation. Fibrobronchoscopy and bronchoalveolar lavage are the gold standard for defining inflammation, but are invasive and not routinely applicable. ${ }^{86}$ 
Omalizumab has been helping the definition of asthma phenotypes and endotypes, thanks also to the identification of new and useful biomarkers to guide the choice of treatment. Therefore, for omalizumab, the selection of patients and the predictability of drug response are still based on the total free IgE level. In this regard, it is demonstrated that a high percentage of patients with severe bronchial obstruction often have total $\mathrm{IgE}$ values $>400 \mathrm{IU} / \mathrm{mL}^{87}$ and that low IgE levels, on the other hand, usually have little therapeutic benefit with omalizumab. ${ }^{88}$ Although lower baseline levels of total IgE were potentially predictive of poor response to omalizumab as emerged from the INNOVATE study, subsequent pooled analysis did not clearly confirm this conclusion and showed treatment benefits regardless of the IgE levels. ${ }^{88}$

As for other possible biomarkers, the level of blood eosinophilia is a parameter that effectively correlates with the response to anti-IL- $5 \mathrm{mAbs}$, especially with $>300$ cells $/ \mu \mathrm{L}$ or better than 500 cells $/ \mu \mathrm{L},{ }^{38}$ while the FeNO reliability data are still partially controversial in determination and follow-up of eosinophilic inflammation ${ }^{89}$ However, the EXTRA study showed that high values of blood eosinophilia and FeNO can positively predict the response to omalizumab, ${ }^{20}$ and patients with these phenotypic characteristics lose treatment benefits more quickly in case of its withdrawal, as demonstrated by the recent XPORT study. ${ }^{21}$

All these aspects increase the difficulty in choosing from one of the two classes of biologics in case of overlapping, although several efficacy and safety data over the long-term use of omalizumab would favor this drug. ${ }^{22}$ Currently, no comparative direct data are available between anti-IgE and antiIL5; so, considering a possible partial overlap between omalizumab- and mepolizumab-ineligible patients, head-to-head comparative trials will be needed to evaluate the efficacy of the two classes of mAbs. For this reason, switch studies from omalizumab to mepolizumab are currently on recruitment. The aim will be to compare these two drugs in terms of improving the QoL and reducing the frequency of clinically significant exacerbations, which may provide additional data to select the most suitable drug. ${ }^{90}$ From a recent meta-analysis study, it has been found that the observed heterogeneity and the different selection criteria for the use of the two drugs do not allow to formulate definitive recommendations for the preferential use of omalizumab versus mepolizumab, and no significant differences in effectiveness were detected. ${ }^{91}$

However, it is important to remember that the atopic condition and the total IgE level at baseline do not affect the efficacy of mepolizumab, as demonstrated by a subanalysis of the DREAM trial. ${ }^{39} \mathrm{~A}$ recent post hoc analysis of patients treated with mepolizumab after an ineffective omalizumab treatment and enrolled in the DREAM, MENSA and SIRIUS studies showed that these patients positively responded to mepolizumab, regardless of the prior use of omalizumab. This result confirms and reinforces the conclusions of previous studies. $^{92}$

An extensive interventional cross-sectional study on a cohort of 670 patients was intended to estimate the potential overlap of patients eligible for treatment with mepolizumab and those eligible for treatment with omalizumab and/or reslizumab. Preliminary data showed a $53 \%$ potential overlap between mepolizumab and omalizumab and a $16.8 \%$ overlap with reslizumab, confirming that common eligibility is often present between the two drug classes. ${ }^{93}$

Promising biomarkers such as periostin will be able to help the clinician. Periostin is an extracellular matrix protein that is also associated with eosinophilic flogosis and is primarily studied to predict the response and monitor the biodrugs such as lebrikizumab and omalizumab. ${ }^{94}$ However, the correlation with eosinophilic inflammation was not always univocal $;{ }^{95}$ therefore, additional data are still needed. In addition, it has been shown that periostin is not just an indicator of type 2 inflammation activated by IL-13. Patients with asthma and high periostin levels have unique characteristics, including eosinophilia, high levels of nitric oxide, acetylsalicylic acid intolerance, nasal polyposis and late-onset asthma. ${ }^{96}$ These features are probably correlated with the involvement of periostin in bronchial remodeling, and this protein may also be associated with poor response to corticosteroids, probably due to tissue remodeling. ${ }^{93}$ In addition, periostin has an accurate predictive power of response to mAbs such as lebrikizumab, tralokinumab and omalizumab, especially if combined with other parameters such as the level of blood eosinophilia and FeNO. ${ }^{20,88}$

The increasing interest about the identification of biomarkers capable of predicting the effectiveness that guides the identification and choice of innovative therapies is represented by the Unbiased BIOmarkers for the Prediction of Respiratory Disease Outcomes project. This project is funded by the European Commission Innovative Medicines Initiative of the European Union, which has proposed a systematic algorithmic approach to patients with severe asthma. ${ }^{97}$

\section{Conclusion}

The increase in therapeutic options for the treatment of asthma has made the subject of phenotyping and personalized therapy very timely. However, it is difficult to choose the right therapeutic target because of the complexity of pathogenesis, 
severity and inflammatory pathways. After the introduction of omalizumab, BT and mepolizumab and the advent of other biologically active drugs, the multimodal approach of the management of patients with severe asthma becomes a key point. This is due to the possible overlap between anti-IgE and anti-IL-5 mAbs (as could be the case in patients with allergy and concomitant hypereosinophilic phenotype) and the difficulty in identification of patients eligible for BT.

The development and application of a broader scale of reproducible, noninvasive, cheap and validated biomarkers will make the treatment selection easier, but those already available, if properly used, can guide the clinician to the right therapeutic option for the right patient.

Pharmacoeconomic aspects must also be considered due to the high direct cost of new therapies. These costs are partially balanced by a better control of asthma; however, they should empower the clinician to the best positioning of current and future treatments. All these actions will avoid waste of valuable resources, especially in the actual socioeconomic context.

\section{Disclosure}

Francesco Menzella participated in contracted research and the clinical trials for Novartis, Sanofi and GlaxoSmithKline. Nicola Facciolongo served as a consultant for Boston Scientific. The other authors report no conflicts of interest in this work.

\section{References}

1. Abraham I, Alhossan A, Lee CS, et al. "Real-life" effectiveness studies of omalizumab in adult patients with severe allergic asthma: systematic review. Allergy. 2016;71(5):593-610.

2. Menzella F, Lusuardi M, Montanari G, et al. Clinical usefulness of mepolizumab in severe eosinophilic asthma. Ther Clin Risk Manag. 2016;12:907-916.

3. Trivedi A, Pavord ID, Castro M. Bronchial thermoplasty and biological therapy as targeted treatments for severe uncontrolled asthma. Lancet Respir Med. 2016;4(7):585-592.

4. Wenzel S. Severe asthma: from characteristics to phenotypes to endotypes. Clin Exp Allergy. 2012;42(5):650-658.

5. Chung KF. Asthma phenotyping: a necessity for improved therapeutic precision and new targeted therapies. J Intern Med. 2016;279(2): 192-204.

6. Lotvall J, Akdis CA, Bacharier LB, et al. Asthma endotypes: a new approach to classication of disease entities within the asthma syndrome. J Allergy Clin Immunol. 2011;127(2):355-360.

7. Moore WC, Meyers DA, Wenzel SE, et al. Identification of asthma phenotypes using cluster analysis in the severe asthma research program. Am J Respir Crit Care Med. 2010;181(4):315-323.

8. Simpson A, Tan VY, Winn J, Svensen M, et al. Beyond atopy: multiple patterns of sensitization in relation to asthma in a birth cohort study. Am J Respir Crit Care Med. 2010;181(11):1200-1206.

9. O’Neil SE, Lundbäck B, Lötvall J. Proteomics in asthma and COPD phenotypes and endotypes for biomarker discovery and improved understanding of disease entities. J Proteomics. 2011;75(1):192-201.

10. Samitas K, Delimpoura V, Zervas E, et al. Anti-IgE treatment, airway inflammation and remodelling in severe allergic asthma: current knowledge and future perspectives. Eur Respir Rev. 2015;24(138):594-601.
11. Humbert M, Busse W, Hanania NA, et al. Omalizumab in asthma: an update on recent developments. JAllergy Clin Immunol Pract. 2014;2(5): 525-536.

12. Rodrigo GJ, Neffen H, Castro-Rodriguez JA. Efficacy and safety of subcutaneous omalizumab vs placebo as add-on therapy to corticosteroids for children and adults with asthma: a systematic review. Chest 2011;139(1):28-35.

13. Lowe PJ, Tannenbaum S, Gautier A, et al. Relationship between omalizumab pharmacokinetics, IgE pharmacodynamics and symptoms in patients with severe persistent allergic (IgE-mediated) asthma. $\mathrm{Br} J$ Clin Pharmacol. 2009;68(1):61-76.

14. Menzella F, Piro R, Facciolongo N, et al. Long-term benefits of omalizumab in a patient with severe non-allergic asthma. Allergy Asthma Clin Immunol. 2011;7(1):9.

15. Forester JP, Calabria CW. Local production of IgE in the respiratory mucosa and the concept of entopy: does allergy exist in nonallergic rhinitis? Ann Allergy Asthma Immunol. 2010;105(4):249-255.

16. Busse WW, Morgan WJ, Gergen PJ, et al. Randomized trial of omalizumab (anti-IgE) for asthma in inner-city children. $N$ Engl J Med. 2011;364(1):1005-1015.

17. Teach SJ, Gill MA, Togias A, et al. Preseasonal treatment with either omalizumab or an inhaled corticosteroid boost to prevent fall asthma exacerbations. J Allergy Clin Immunol. 2015;136(6):1476-1485.

18. Giménez-Arnau AM, Toubi E, Marsland AM, Maurer M. Clinical management of urticaria using omalizumab: the first licensed biological therapy available for chronic spontaneous urticaria. J Eur Acad Dermatol Venereol. 2016;30(Suppl 5):25-32.

19. Bachert C, Gevaert P, Hellings P. Biotherapeutics in chronic rhinosinusitis with and without nasal polyps. J Allergy Clin Immunol Pract. 2017. pii:S2213-2198(17)30321-5. [Epub ahead of print]

20. Hanania NA, Wenzel S, Rosén K, et al. Exploring the effects of omalizumab in allergic asthma: an analysis of biomarkers in the EXTRA study. Am J Respir Crit Care Med. 2013;187(8):804-811.

21. Ledford D, Busse W, Trzaskoma B, et al. A randomized multicenter study evaluating Xolair persistence of response after long-term therapy. J Allergy Clin Immunol. 2017;140(1):162-169.e2.

22. Menzella F, Galeone C, Formisano D, et al. Real-life efficacy of omalizumab after 9 years of follow-up. Allergy Asthma Immunol Res. 2017;9(4): 368-372.

23. Menzella F, Facciolongo N, Piro R, et al. Clinical and pharmacoeconomic aspects of omalizumab: a 4-year follow-up. Ther Adv Respir Dis. 2012;6(2):87-95.

24. Genentech. A Study of MEMP1972A in Patients with Allergic Asthma Inadequately Controlled on Inhaled Steroids and A Second Controller (COSTA); 2012. Available from: https:/clinicaltrials.gov/ct2/show/ NCT01582503. Accessed June 6, 2017. ClinicalTrials.gov Identifier: NCT01582503. Accessed June 6, 2017.

25. Harris JM, Maciuca R, Bradley MS, et al. A randomized trial of the efficacy and safety of quilizumab in adults with inadequately controlled allergic asthma. Respir Res. 2016;17(1):29.

26. Genentech. A Study to Investigate the Safety, Tolerability, and Pharmacokinetics of MEMP1972A in Patients with Allergic Rhinitis; 2010. Available from: https://clinicaltrials.gov/ct2/show/ NCT01160861. Accessed June 6, 2017. ClinicalTrials.gov Identifier: NCT01160861. Accessed June 6, 2017.

27. Genentech. A Study of MEMP1972A in the Prevention of Allergen-Induced Airway Obstruction in Patients with Mild Asthma (SOLARIO); 2010. Available from: https://clinicaltrials.gov/ct2/show/ NCT01196039. Accessed June 6, 2017. ClinicalTrials.gov Identifier: NCT01196039. Accessed June 6, 2017.

28. Gauvreau GM, Harris JM, Boulet LP, et al. Targeting membraneexpressed IgE B cell receptor with an antibody to the M1 prime epitope reduces IgE production. Sci Transl Med. 2014;6(243):243ra85.

29. Arm JP, Bottoli I, Skerjanec A, et al. Pharmacokinetics, pharmacodynamics and safety of QGE031 (ligelizumab), a novel high-affinity anti-IgE antibody, in atopic subjects. Clin Exp Allergy. 2014;44(11): $1371-1385$. 
30. Novartis Pharmaceuticals. Efficacy and Safety of QGE031 versus Placebo and Omalizumab in Patients Aged 18-75 Years With Asthma; 2012. Available from: https://clinicaltrials.gov/ct2/ show?term=CQGE031B2201. Accessed July 31, 2017. NLM Identifier: NCT01716754. Accessed July 31, 2017.

31. Gauvreau GM, Arm JP, Boulet LP, et al. Efficacy and safety of multiple doses of QGE031 (ligelizumab) versus omalizumab and placebo in inhibiting allergen-induced early asthmatic responses. J Allergy Clin Immunol. 2016;138(4):1051-1059.

32. Stone KD, Prussin C, Metcalfe DD. IgE, mast cells, basophils, and eosinophils. J Allergy Clin Immunol. 2010;125(2 Suppl 2):S73-S80.

33. Tanaka H, Komai M, Nagao K, et al. Role of interleukin-5 and eosinophils in allergen-induced airway remodeling in mice. Am J Respir Cell Mol Biol. 2004;31(1):62.

34. Wardlaw AJ, Brightling CE, Green R, Woltmann G, Bradding P, Pavord ID. New insights into the relationship between airway inflammation and asthma. Clin Sci (Lond). 2002;103(2):201-211.

35. Legrand F, Klion AD. Biologic therapies targeting eosinophils: current status and future prospects. J Allergy Clin Immunol Pract. 2015;3(2):167-174.

36. Leckie MJ, ten Brinke A, Khan J, et al. Effects of an interleukin- 5 blocking monoclonal antibody on eosinophils, airway hyper-responsiveness, and the late asthmatic response. Lancet. 2000;356(9248):2144-2148.

37. Flood-Page P, Menzies-Gow A, Phipps S, et al. Anti-IL-5 treatment reduces deposition of ECM proteins in the bronchial subepithelial basement membrane of mild atopic asthmatics. J Clin Invest. 2003;112(7):1029-1036.

38. Ortega HG, Liu MC, Pavord ID, et al. Mepolizumab treatment in patients with severe eosinophilic asthma. NEngl J Med. 2014;371(13): 1198-1207.

39. Pavord ID, Korn S, Howarth P, et al. Mepolizumab for severe eosinophilic asthma (DREAM): a multicentre, double-blind, placebocontrolled trial. Lancet. 2012;380(9842):651-659.

40. BelEH, Wenzel SE, Thompson PJ, etal. Oral glucocorticoid-sparing effect of mepolizumab in eosinophilic asthma. N Engl J Med. 2014;371(13): 1189-1197.

41. Chupp GL, Bradford ES, Albers FC, et al. Efficacy of mepolizumab add-on therapy on health-related quality of life and markers of asthma control in severe eosinophilic asthma (MUSCA): a randomised, double-blind, placebo-controlled, parallel-group, multicentre, phase 3b trial. Lancet Respir Med. 2017;5(5):390-400.

42. Available from: http://www.fda.gov/NewsEvents/Newsroom/PressAnnouncements/ucm471031.htm. Accessed May 27, 2017.

43. Available from: http://www.ema.europa.eu/ema/index.jsp?curl=pages/ medicines/human/medicines/003860/human_med_001933. jsp\&mid=WC0b01ac058001d124. Accessed May 27, 2017.

44. Castro M, Mathur S, Hargreave F, et al. Reslizumab for poorly controlled, eosinophilic asthma: a randomized, placebo-controlled study. Am J Respir Crit Care Med. 2011;184(10):1125-1132.

45. Available from: https://www.fda.gov/NewsEvents/Newsroom/PressAnnouncements/ucm491980.htm. Accessed May 28, 2017.

46. Kolbeck R, Kozhich A, Koike M, et al. MEDI-563, a humanized anti-IL-5 receptor alpha $\mathrm{mAb}$ with enhanced antibody-dependent cell-mediated cytotoxicity function. JAllergy Clin Immunol. 2010;125(6):1344-1353.

47. Menzella F, Lusuardi M, Galeone C, Facciolongo N, Zucchi L. The clinical profile of benralizumab in the management of severe eosinophilic asthma. Ther Adv Respir Dis. 2016;10(6):534-548.

48. Laviolette M, Gossage DL, Gauvreau G, et al. Effects of benralizumab on airway eosinophils in asthmatic patients with sputum eosinophilia. J Allergy Clin Immunol. 2013;132(5):1086-1096.

49. Ghazi A, Trikha A, Calhoun WJ. Benralizumab - a humanized mAb to IL-5Ralpha with enhanced antibody-dependent cell-mediated cytotoxicity - a novel approach for the treatment of asthma. Expert Opin Biol Ther. 2012;12(1):113-118.

50. Castro M, Wenzel SE, Bleecker ER, et al. Benralizumab, an antiinterleukin 5 receptor alpha monoclonal antibody, versus placebo for uncontrolled eosinophilic asthma: a phase $2 \mathrm{~b}$ randomised dose-ranging study. Lancet Respir Med. 2014;2(11):879-890.
51. FitzGerald JM, Bleecker ER, Nair P, et al. Benralizumab, an antiinterleukin-5 receptor $\alpha$ monoclonal antibody, as add-on treatment for patients with severe, uncontrolled, eosinophilic asthma (CALIMA): a randomised, double-blind, placebo-controlled phase 3 trial. Lancet. 2016;388(10056):2128-2141.

52. Bleecker ER, FitzGerald JM, Chanez P, et al. Efficacy and safety of benralizumab for patients with severe asthma uncontrolled with high-dosage inhaled corticosteroids and long-acting $\beta_{2}$-agonists (SIROCCO): a randomised, multicentre, placebo-controlled phase 3 trial. Lancet. 2016;388(10056):2115-2127.

53. Nair P, Wenzel S, Rabe KF, et al. Oral glucocorticoid-sparing effect of benralizumab in severe asthma. $N$ Engl J Med. 2017. [Epub ahead of print].

54. Nowak RM, Parker JM, Silverman RA, et al. A randomized trial of benralizumab, an antiinterleukin 5 receptor $\alpha$ monoclonal antibody, after acute asthma. Am J Emerg Med. 2015;33(1):14-20.

55. Agrawal S1, Townley RG. Role of periostin, FENO, IL-13, lebrikzumab, other IL-13 antagonist and dual IL-4/IL-13 antagonist in asthma. Expert Opin Biol Ther. 2014;14(2):165-681.

56. Gandhi NA, Pirozzi G, Graham NMH. Commonality of the IL-4/ IL-13 pathway in atopic diseases. Expert Rev Clin Immunol. 2017;13(5):425-437.

57. Vatrella A, Fabozzi I, Calabrese C, et al. Dupilumab: a novel treatment for asthma. J Asthma Allergy. 2014;7:123-130.

58. Wenzel S, Ford L, Pearlman D, et al. Dupilumab in persistent asthma with elevated eosinophil levels. N Engl J Med. 2013;368(26):2455-2466.

59. Wenzel S, Castro M, Corren J, et al. Dupilumab efficacy and safety in adults with uncontrolled persistent asthma despite use of mediumto-high-dose inhaled corticosteroids plus a long-acting $\beta 2$ agonist: a randomised double-blind placebo-controlled pivotal phase $2 \mathrm{~b}$ doseranging trial. Lancet. 2016;388(10039):31-44.

60. Maselli DJ, Keyt H, Rogers L. Profile of lebrikizumab and its potential in the treatment of asthma. J Asthma Allergy. 2015;8:87-92.

61. Corren J, Lemanske RF, Hanania NA, et al. Lebrikizumab treatment in adults with asthma. $N$ Engl $J$ Med. 2011;365(12):1088-1098.

62. Hanania NA, Noonan M, Corren J, et al. Lebrikizumab in moderate-tosevere asthma: pooled data from two randomised placebo-controlled studies. Thorax. 2015;70(8):748-756.

63. Hanania NA, Korenblat P, Chapman KR, et al. Efficacy and safety of lebrikizumab in patients with uncontrolled asthma (LAVOLTA I and LAVOLTA II): replicate, phase 3 , randomised, double-blind, placebocontrolled trials. Lancet Respir Med. 2016;4(10):781-796.

64. Piper E, Brightling C, Niven R, et al. A phase II placebo-controlled study of tralokinumab in moderate-to-severe asthma. Eur Respir J. 2013;41(2):330-338.

65. Brightling CE, Chanez P, Leigh R, et al. Efficacy and safety of tralokinumab in patients with severe uncontrolled asthma: a randomised, double-blind, placebo-controlled, phase $2 \mathrm{~b}$ trial. Lancet Respir Med. 2015;3(9):692-701.

66. Arima M, Fukuda T. Prostaglandin $\mathrm{D}_{2}$ and $\mathrm{T}(\mathrm{H}) 2$ inflammation in the pathogenesis of bronchial asthma. Korean JIntern Med. 2011;26(1):8-18.

67. Chevalier E1, Stock J, Fisher T, et al. Cutting edge: chemoattractant receptor-homologous molecule expressed on $\mathrm{Th} 2$ cells plays a restricting role on IL-5 production and eosinophil recruitment. J Immunol. 2005;175(4):2056-2060.

68. Erpenbeck VJ, Vets E, Gheyle L, et al. Pharmacokinetics, safety, and tolerability of fevipiprant (QAW039), a novel CRTh2 receptor antagonist: results from 2 randomized, phase 1, placebo-controlled studies in healthy volunteers. Clin Pharmacol Drug Dev. 2016;5(4):306-313.

69. Erpenbeck VJ, Popov TA, Miller D, et al. The oral CRTh2 antagonist QAW039 (fevipiprant): a phase II study in uncontrolled allergic asthma. Pulm Pharmacol Ther. 2016;39:54-63.

70. Gonem S, Berair R, Singapuri A, et al. Fevipiprant, a prostaglandin D2 receptor 2 antagonist, in patients with persistent eosinophilic asthma: a single-centre, randomised, double-blind, parallel-group, placebocontrolled trial. Lancet Respir Med. 2016;4(9):699-707.

71. Available from: https://www.accessdata.fda.gov/cdrh_docs/pdf8/ P080032b.pdf. Accessed May 30, 2017 
72. Cox G, Thomson NC, Rubin AS, et al; AIR Trial Study Group. Asthma control during the year after bronchial thermoplasty. $N$ Engl J Med. 2007;356(13):1327-1337.

73. Pavord ID, Cox G, Thomson NC, et al; RISA Trial Study Group. Safety and efficacy of bronchial thermoplasty in symptomatic, severe asthma. Am J Respir Crit Care Med. 2007;176(12):1185-1191.

74. Castro M, Rubin AS, Laviolette M, et al; AIR2 Trial Study Group. Effectiveness and safety of bronchial thermoplasty in the treatment of severe asthma: a multicenter, randomized, double-blind, sham-controlled clinical trial. Am J Respir Crit Care Med. 2010;181(2):116-124.

75. Trivedi A, Pavord ID, Castro M. Bronchial thermoplasty and biological therapy as targeted treatments for severe uncontrolled asthma. Lancet Respir Med. 2016;4(7):585-592.

76. Menzella F, Zucchi L, Piro R, et al. A budget impact analysis of bronchial thermoplasty for severe asthma in clinical practice. Adv Ther. 2014;31(7):751-761.

77. Zein JG, Menegay MC, Singer ME, et al. Cost effectiveness of bronchial thermoplasty in patients with severe uncontrolled asthma. J Asthma. 2016;53(2):194-200.

78. Pretolani M, Dombret MC, Thabut G, et al. Reduction of airway smooth muscle mass by bronchial thermoplasty in patients with severe asthma. Am J Respir Crit Care Med. 2014;190(12):1452-1454.

79. Denner DR, Doeing DC, Hogarth DK, Dugan K, Naureckas ET, White SR. Airway inflammation after bronchial thermoplasty for severe asthma. Ann Am Thorac Soc. 2015;12(9):1302-1309.

80. Ryan DM, Fowler SJ, Niven RM. Reduction in peripheral blood eosinophil counts after bronchial thermoplasty. JAllergy Clin Immunol. 2016;138(1):308-310.

81. Debray MP, Dombret MC, Pretolani M, et al. Early computed tomography modifications following bronchial thermoplasty in patients with severe asthma. Eur Respir J. 2017;49(3):1601565.

82. Arcispedale Santa Maria Nuova-IRCCS. Bronchial thermoplasty: effect on neuronal and chemosensitive component of the bronchial mucosa (BT-ASMN); 2014. Available from: https://clinicaltrials.gov/ ct2/show/NCT01839591. Accessed April 30, 2017. NLM Identifier: NCT01839591. Accessed April 30, 2017.

83. Doeing DC, Mahajan AK, White SR, et al. Safety and feasibility of bronchial thermoplasty in asthma patients with very severe fixed airflow obstruction: a case series. J Asthma. 2013;50(2):215-218.

84. Fajt ML, Wenzel SE. Development of new therapies for severe asthma. Allergy Asthma Immunol Res. 2017;9(1):3-14.

85. Wenzel SE. Asthma phenotypes: the evolution from clinical to molecular approaches. Nat Med. 2012;18(5):716-725.

86. Lommatzsch SE, Martin RJ, Good JT Jr. Importance of fiberoptic bronchoscopy in identifying asthma phenotypes to direct personalized therapy. Curr Opin Pulm Med. 2013;19(1):42-48.

87. Davila I, Valero A, Entrenas LM, et al. Relationship between serum total IgE and disease severity in patients with allergic asthma in Spain. J Investig Allergol Clin Immunol. 2015;25(2):120-127.
88. Bousquet J, Rabe K, Humbert M, et al. Predicting and evaluating response to omalizumab in patients with severe allergic asthma. Respir Med. 2007;101(7):1483-1492.

89. Wagener AH, de Nijs SB, Lutter R, et al. External validation of blood eosinophils, FE(NO) and serum periostin as surrogates for sputum eosinophils in asthma. Thorax. 2015;70(2):115-120.

90. GlaxoSmithKline. Omalizumab to mepolizumab switch study in severe eosinophilic asthma patients; 2016. Available from: https://clinicaltrials.gov/ct2/show/ NCT02654145. NLM Identifier: NCT02654145. Accessed may 30, 2017.[NLM Identifier: NCT02654145].

91. Nachef Z, Krishnan A, Mashtare T, Zhuang T, Mador MJ. Omalizumab versus Mepolizumab as add-on therapy in asthma patients not well controlled on at least an inhaled corticosteroid: a network meta-analysis. J Asthma. 2017:1-12.

92. Magnan A, Bourdin A, Prazma CM, et al. Treatment response with mepolizumab in severe eosinophilic asthma patients with previous omalizumab treatment. Allergy. 2016;71(9):1335-1344.

93. GlaxoSmithKline. Cross-sectional study for identification and description of severe asthma patients; 2014. Available from: https://clinicaltrials.gov/ct2/show/ NCT02293265. NLM Identifier: NCT02293265. Accessed May 30, 2017.

94. Parulekar AD, Atik MA, Hanania NA. Periostin, a novel biomarker of TH2-driven asthma. Curr Opin Pulm Med. 2014;20(1):60-65.

95. Westerhof GA, Korevaar DA, Amelink M, et al. Biomarkers to identify sputum eosinophilia in different adult asthma phenotypes. Eur Respir J. 2015;46(3):688-696.

96. Izuhara $\mathrm{K}$, Ohta S, Ono J. Using periostin as a biomarker in the treatment of asthma. Allergy Asthma Immunol Res. 2016;8(6):491-498.

97. Bel EH, Sousa A, Fleming L, et al. Unbiased biomarkers for the prediction of respiratory disease outcome (U-BIOPRED) consortium, consensus generation. Diagnosis and definition of severe refractory asthma: an international consensus statement from the innovative medicine initiative (IMI). Thorax. 2011;66(10):910-917.

98. Chung KF, Wenzel SE, Brozeket JL, et al. International ERS/ATS guidelines on definition, evaluation and treatment of severe asthma. Eur Respir J. 2014;43(2):343-373.

99. A budget impact analysis of bronchial thermoplasty for severe asthma in clinical practice. Adv Ther. 2014;31(7):751-761.

100. Menzella F, Lusuardi M, Montanari G, Galeone C, Facciolongo N, Zucchi L. Clinical usefulness of mepolizumab in severe eosinophilic asthma. Ther Clin Risk Manag. 2016;12:907-916.

101. Registry of the Ministry of Health nr. 75/2017 January 19 2017, Nucala. (n. 332/2017). (17A01570) (GU nr.49 / 28-02-2017).

102. Wu AC, Paltiel AD, Kuntz KM, Weiss ST, Fuhlbrigge AL. Cost-effectiveness of omalizumab in adults with severe asthma:Results from the asthma policy model. JAllergy Clin Immunol. 2007;120(5):1146-1152.

103. Mahajan AK, Hogarth DK. Payer coverage for bronchial thermoplasty: shifting the traditional paradigm for refractory asthma therapy. Chest. 2013;144(3):1051-1054
Journal of Asthma and Allergy

\section{Publish your work in this journal}

The Journal of Asthma and Allergy is an international, peer-reviewed open access journal publishing original research, reports, editorials and commentaries on the following topics: Asthma; Pulmonary physiology; Asthma related clinical health; Clinical immunology and the immunological basis of disease; Pharmacological interventions and new therapies. This journal is included in PubMed. The manuscript management system is completely online and includes a very quick and fair peer-review system, which is all easy to use. Visit http://www. dovepress.com/testimonials.php to read real quotes from published authors. 